multicêntrico em cão com metástase em SNC. Foi atendido no Hospital Veterinário da FMVZ - Unesp - Botucatu, um cão da raça Labrador Retriever, fêmea com 2 anos de idade. Apresentava histórico de hiporexia, dispnéia e aumento de volume abdominal há 20 dias. Ao exame clínico observou-se aumento dos linfonodos submandibulares, pré-escapulares e popliteos, mucosas hipocoradas, hepatomegalia e esplenomegalia à palpação abdominal $\mathrm{e}$ abafamento dos sons cardíacos e respiratórios à auscultaçào cardio-pulmonar. O hemograma revelou anemia macrocítica normocrômica e trombocitopenia moderada. O cálcio, a urinálise e o perfil renal apresentavam-se normais. O perfil hepático estava alterado, apresentando aumento das enzimas alanina-aminotransferase (ALT), fosfatase alcalina (FA) e gamaglutamiltransferase (GGT), além de diminuição da proteina total e albumina. As radiografias torácica e abdominal revelaram a presença de efusào pleural, linfonodo mediastinal aumentado, hepatomegalia e esplenomegalia. Através da citologia aspirativa dos linfonodos constatou-se a presença de linfoma linfocítico. Dessa forma, foi iniciada a quimioterapia com ciclofosfamida, vincristina e prednisona (COP) nas doses recomendadas pela literatura. Após a quinta semana de tratamento, o cào começou a apresentar tremores na cabeça (convulsão parcial), hiporexia, apatia e emese. Os exames laboratoriais estavam todos normais e foi feito tratamento sintomático e de suporte. O quadro clínico evoluiu com o surgimento de outras alteraçòes neurológicas, como alteração no estado de consciência, ataxia seguida de tetraparesia, incoordenação da cabeça, alteraçòes em nervos cranianos e reflexos espinhais aumentados. Foi entào realizada a colheita de líquor no qual evidenciou-se neoplasia da série linfóide, confirmando metástase em SNC. Foi suspensa a terapia anterior e iniciada quimioterapia com lomustina na tentativa de atingir o SNC. O animal apresentou piora do estado clínico, sendo indicado eutanásia do animal após dois dias do início da terapia com lomustina. À necrópsia observou-se congestão cerebral no exame macroscópico. A histopatologia revelou invasão das células neoplásicas em córtex cerebelar e cerebelo. Este relato torna-se importante devido à apresentação clínica incomum de linfoma multicêntrico e para evidenciar a importância do exame de líquor no diagnóstico de neoplasias em SNC.

\title{
93 - Tumor endócrino de pâncreas associado a síndrome hipoglicêmica. Relato de caso e caracterização imuno-histoquímica
}

Málaga, S.K.'; Sá, L.R.M.²; Mariano, C.S. '; Diloreto, C. ${ }^{3}$; Nonogaki, S. ${ }^{3}$
1- Médica Veterinária Autônoma

2- Departamento de Patologia da Faculdade de Medicina Veterinária e Zootecnia da Universidade de São Paulo, São Paulo-SP

3- Divisão de Patologia, Instituto Adolfo Lutz, São Paulo-SP

Os tumores pancreáticos endócrinos são neoplasias incomuns e estudos imuno-histoquímicos têm demonstrado que muitas vezes estas neoplasias podem produzir e secretar vários hormônios. Nos càes, os tumores endócrinos pancreáticos são geralmente associados a hiperinsulinemismo e hipoglicemia. O presente relato tem por objetivo descrever um caso de tumor endócrino de pâncreas produtor de múltiplos hormônios em um cào que apresentava síndrome hipoglicêmica, salientando os diagnósticos diferenciais. Um cão, sem raça definida, fêmea, de 13 anos foi examinada clinicamente por apresentar tremores, quedas freqüentes, ataxia dos quatro membros, incapacidade de manter-se em estação, micção em decúbito, polifagia, poliúria e polidipsia. O exame clínico revelou hipotermia, mucosas hipocoradas, sensibilidade abdominal e lombar, tetraparesia, atrofia muscular moderada nos. membros pélvicos. Os exames laboratoriais revelaram hipoglicemia grave $(19 \mathrm{mg} / \mathrm{dl})$, valores de sódio e potássio dentro dos valores de referência $(131 \mathrm{mEq} / 1$ e $5,10 \mathrm{mEq} / 1$, respetivamente) e creatinina elevada $(2,67 \mathrm{mg} / \mathrm{dl})$. Apesar do tratamento instituído o animal entrou em estado epiléptico com hipoglicemia não responsiva à terapia. Diante do estado clínico grave, mau prognóstico mediante à suspeita de insulinoma e a incapacidade financeira do proprietário de manter o animal, foi realizada a eutanásia. Procedeu-se o exame necroscópico que revelou 
formação nodular de $1,5 \times 1,0 \times 1,0 \mathrm{~cm}$, em pólo caudal do pâncreas, com consistência firme, aspecto lobulado e superficie de corte esbranquiçada com áreas acastanhadas. Fragmento do pâncreas com o nódulo foi collhido, fixado em formol e encaminhado para processamento segundo técnica padrào para exame histopatológico e corado por hematoxilina e eosina. Cortes histopatológicos do pâncreas foram submetidos a reação de imuno-histoquímica utilizando sistema LSAB plus da Dako, para caracterização dos possíveis hormônios produzidos pelas células neoplásicas. Microscopicamente, a formação se caracterizava por ser encapsulada, multilobulada composta por células neoplásicas poliédricas ou arredondadas, com núcleos centrais ou excêntricos, que apresentam cromatina frouxa, citoplasma ligeiramente eosinofilico e com granulação fina. Estas células se arranjam em pequenos agrupamentos sólidos separados por septos de tecido conjuntivo vascularizado e delicado. A cápsula é fibrosa e exibe células com pigmentos acastanhados grosseiros. O exame imuno-histoquímico caracterizou este tumor como tumor endócrino com produção de insulina, gastrina e somatostatina. As alterações clínicas observadas neste caso são semelhantes as relatadas na literatura nos casos de hipoglicemia. Nos cães idosos as causas mais comuns de hipoglicemia são insuficiência hepática, neoplasia de células $B$ pancreáticas, neoplasia extrapancreática, hipoadrenocorticismo e sepsis. A hipoglicemia nos casos de hipoadrenocorticismo e insuficiência hepática costumam ser brandas e acompanhadas de hiponatremia, hipercalemia, elevação da enzimas hepáticas e hipoproteinemia. No presente caso, a grave hipoglicemia não responsiva à terapia, os valores de sódio e potássio normais e ausência de outras alteraçōes clínicas sugestivas de insuficiência hepática ou sepsis, levaram ao diagnóstico clínico de neoplasia de células $B$. O anatomopatológico confirmou a suspeita clínica e ainda caracterizou a neoplasia como multihormonal. Considera-se que as células neoplásicas produzam e secretam os demais hormônios, porém o aumento da insulina mascara os efeitos dos demais hormônios. Concluise, com a associação clínico anatomopatológica tratar-se de um tumor endócrino multihormonal, sendo a insulina o hormônio relacionado com a síndrome clinica relatada.

\section{4 - Leucemia monocítica em cão. Relato de caso}

Bonello, F.L.'; Ciarlini, P.C.' ; Feitosa, M.M. '; Machado, G.F.'; Silva, I.C.'
1- Curso de Medicina Veterinária da Faculdade de Medicina Veterinária e Agrárias da Universidade Estadual Paulista, Campus de Araçatuba, Araçatuba-SP

As proliferaçòes neoplásicas envolvendo monócitos ou seus precursores são raras, porém foram reportadas $\mathrm{em}$ algumas espécies animais. Normalmente apresentam-se como doença aguda num paciente comprometido com severas citopenias, quase que invariavelmente levando o animal a óbito. As leucemias monocíticas podem ser classificadas em dois subtipos - M5a e M5b, dependendo da maturidade das células da linhagem monocítica. O objetivo deste trabalho é relatar um caso de leucemia monocítica aguda num cào que veio a óbito uma semana após o diagnóstico, e acrescentar novas informações ao conjunto daquelas disponíveis na literatura. Um cào macho, de sete anos, da raça Pastor Alemào foi atendido no Hospital Veterinário Luiz Quintiliano de Oliveira - Unesp - Câmpus de Araçatuba, com episódios de vômito e diarréia líquiida amarelada. Apresentava descamação micácea generalizada e secreções nasal e ocular purulentas, além de onicogrifose e mucosas hipocoradas. Dos exames complementares, os achados radiográficos revelaram pneumonia e cardiomegalia, enquanto que o hemograma evidenciou anemia normocítica normocrômica sem sinais de resposta medular, eritrócitos em "rouleaux" e raros esquizócitos, além de elevada leucocitose $(362.000 / \mathrm{mL})$. Cerca de $80 \%$ dos leucócitos apresentavam características monocitóides, com intensa vacuolização citoplasmática. Nucléolos aberrantes e figuras de mitose foram achados freqüentes. Os poucos neutrófilos presentes apresentavam hipersegmentaçào. A análise do esfregaço da medula óssea revelou predominância de células monocitóides com características semelhantes às observadas no sangue periférico, além de raras células eritróides e ausência de megacariócitos. Os achados macroscópicos de necropsia evidenciaram aumento de volume do baço e linfonodos, bem como nódulos esbranquiçados 